\title{
Integrating Veteran Experiences into Engineering Design: Veteran-led Stu- dent Development of High-power Rocket Competition Team
}

\section{Thomas L. Davis, Kent State University}

Thomas Davis is a graduate student in the Master of Technology program at Kent State University. He holds a bachelors degree in aeronautical systems engineering technology from Kent State University. Prior to joining the Kent State student body, Mr. Davis held operator and technical service request specialist positions at Forest City Technologies, Inc. for a total of 16 years. He is currently a staff sergeant in the Ohio Army National Guard, where he has served as a helicopter maintainer for 15 years.

\section{Dr. D. Blake Stringer, Kent State University}

BLAKE STRINGER, Ph.D. is an assistant professor of at Kent State University. He is the founding faculty member of the university's aerospace engineering program. Prior to joining the faculty at Kent State, Dr. Stringer served in the Army for 20 years as an army aviator, West Point faculty member, and research engineer. He holds a bachelors degree in aerospace engineering from the US Military Academy, a masters degree in aerospace engineering from Georgia Tech, and a doctorate in mechanical and aerospace engineering from the University of Virginia. Prior to his retirement, he led the Army Research Laboratory's vehicle propulsion division, conducting basic and applied research of engine and drive system technologies. His research interests are varied and include unmanned aerial systems, the aerodynamics of vertical axis wind turbines, rotating mechanical components, rotordynamics, and engineering education pedagogy. As an aviator, he has been rated in both rotary and fixed-wing platforms. He also holds a FAA commercial airman's certificate.

\section{Dr. Maureen Regan McFarland, Kent State University}

MAUREEN McFARLAND is currently the Aeronautics Senior Program Director and an assistant professor at Kent State University. Prior to joining the faculty at Kent State, Dr. McFarland served in the Marine Corps as a navigator at which time she transitioned to the Marine Corps Reserve, retiring after 20 years of service. She holds a bachelor's degree in aerospace engineering from the US Naval Academy, a master's degree in business from Boston University, and a $\mathrm{PhD}$ in educational psychology at Kent State University. Her research interests include assessment, effective teaching practices using instructional technology, and engineering education pedagogy. 


\title{
Integrating Veteran Experiences into Engineering Design: Veteran-Led Student Development of High-Power Rocket Competition Team
}

\begin{abstract}
In 2016, students at Kent State University (KSU) were invited to participate in the Midwest High-Power Rocket Competition, an annual design competition hosted by the Minnesota Space Grant Consortium. Having little to no knowledge of high-power model rocketry, this group of college students petitioned the college to sponsor a team. Upon receiving dean approval, the group of students needed to organize, delineate responsibilities, secure funding, design and build a rocket, perform flight tests, conduct outreach, establish safety protocols, document their work, travel and compete in the competition. Moreover, they needed to accomplish all this within six months and outside of the normal classroom environment.
\end{abstract}

The group consisted of students from a variety of majors to include aerospace engineering, aeronautical systems engineering technology, mechanical engineering technology, and flight technology. Among these were three former active-duty or national guard veterans.

The literature already documents the attributes of student veterans in terms of their potential within the engineering community. This paper describes the design competition and documents the actions of the team through the student design process. It then describes the veterans' roles and integration in the project, specifically how their veteran experiences directly influenced the team's success. Finally, it describes these veterans' impact on model rocketry at the institution as a whole and their legacy in subsequent competition teams.

\section{Introduction}

Universities have experienced significant growth of student-veteran enrollment within the last decade as a result of the Post 9/11 Veterans Educational Assistance Act of 2008 [1]. Studentveterans and university administrators continue development of effective transitioning programs focused on veterans' needs within the institutional administrative processes. Many initiatives also exist that attempt to draw student-veterans into science, technology, engineering, and mathematics (STEM) programs, as well as other management-based curricula [1], [2]. While these types of initiatives are well-documented, veteran participation in student engineering organizations and design competitions is relatively undocumented [3].

This paper discusses student-veteran contributions to one such design group, the Kent State University High-Power Rocket Club. It is written from the perspective of the group's first project manager, who is a student-veteran with 14 years of military experience, to include combat deployment, and is currently a staff sergeant in the Ohio National Guard.

This paper documents the challenges faced by forming the new student organization on campus, forming the design team, and implementing solutions to the design problem, while detailing specific student-veteran attributes that greatly contributed to the success of the team. The paper then discusses how the actions of the student-veterans laid the organizational framework to have 
a lasting impact on the college and university, and their implications for the broader engineering community. The paper also discusses the effect of the design competition and other students on the student-veterans themselves.

\section{Competition Background}

In fall 2016, Kent State University received a solicitation to host a subsequent year of the Annual Midwest High-Power Rocket Competition. Having no previous exposure to the competition yet initially intrigued, students involved in the proposal realized that, if they were to be part of hosting the event in the future, they should first participate in the event. Obtaining permission from competition authorities to enter past the letter of intent deadline, interested students eagerly petitioned the college for permission to assemble and resource a team and began recruiting its members. Within a few weeks, by November 2016, the KSU High-Power Rocket Club was a sanctioned university student organization and consisted of 15 persons of varying race, age, sex, and degree programs. The team also included three student-veterans from the Ohio National Guard. Two of the three student-veterans were elected by the team to become leaders within the group, accounting for $40 \%$ of the team leadership positions.

The competition objective was to design and build a high-power rocket that could achieve the same altitude using two different-class motors while surviving two successive launches. Since the two motors provided different amounts of thrust, the same-altitude constraint required a drag system design with the ability to slow the rocket's ascent when using the larger motor. The competition also required a means for directly measuring the airspeed of the rocket during flight (such as a pitot tube), rather than the use of an indirect means (such as GPS).

Although it began the design, build and fly project two months past the original deadline, during actual competition the team's rocket performed admirably. The team's engineering design solutions experienced only minor faults. Furthermore, during the team's oral presentation at the competition, judges lauded the team's simple, yet inventive, fully mechanical drag device as "ingenious." The design team was awarded "honorable mention," placing fourth out of 18 teams. This surpassed even the team's expectations given their time constraints and their "newness" to the high-power rocketry environment (see Figure 1). The placement of student-veterans in key roles greatly contributed to these achievements.

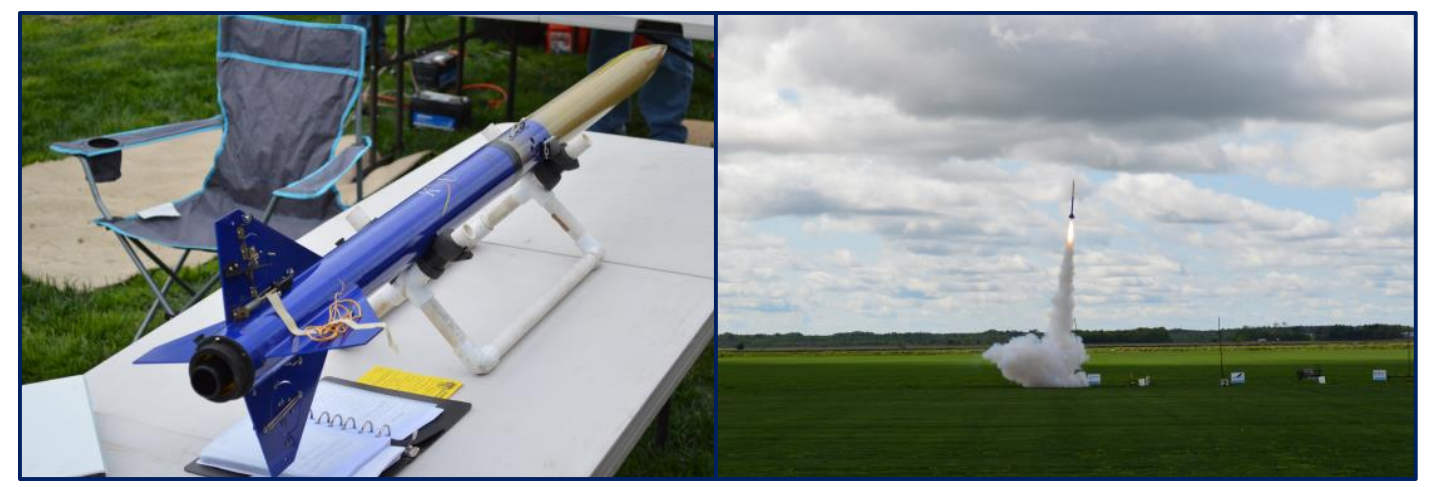

Figure 1: Team rocket at the competition inspection stand (left) and at launch (right) 


\section{Competition Challenges}

The team challenges can be categorized into three areas: (1) technical, (2) operational, and (3) logistical. The technical challenges simply pertain to the requirements of the competition itself and were detailed above. The operational and logistical categories were more involved and are presented in Table 1.

Table 1: Competition Challenges

\begin{tabular}{|c|c|c|}
\hline Technical Challenge & Operational Challenge & Logistical Challenge \\
\hline Competition objectives & Late entry & Funding \\
\hline Competition design constraints & Experience level & Campus launch sites \\
\hline Other competition requirements & Safety & Managing deliverables \\
\hline
\end{tabular}

Most operational hurdles were unique to the team itself. Entering the competition two months late with no previous high-power rocketry experience while competing against 17 other seasoned teams gave the team a sense that it was already at a disadvantage. This generated an initial cloud of uncertainty which surrounded the team and caused it to question at times its ability to design a functional, competition-winning rocket. Additionally, the team's inexperience with handling and using hazardous materials (e.g., rocket motors and explosive charges) required acquired knowledge and application of risk-management procedures in order to foster a culture of safety and mitigate complacency over the course of the time-constrained design process.

Although having a smaller effect on the competition tasks, overall the logistical challenges were just as important as the technical and operational challenges. These challenges were primarily driven by the necessity to formalize the student-organization within the university administrative structure in a short time-frame in order to secure funding and receive appropriate approvals for conducting varied rocket activities on campus.

A noted requirement of the competition which did not tie into technical challenges but significantly impacted logistic requirements was the stated need for educational and community outreach. During the course of the design, build and fly competition portions of the challenge, the team directly led or provided support for three institutional camps and two community outreach events. These camps focused primarily on middle-school and high-school students that are underrepresented in STEM education. Coordination for these outreach activities had to be completed in tandem with the technical and operational tasks. This created another level of difficulty, specifically for the team's leadership. Student-veteran attributes became apparent in planning and conducting these events. The student-veterans treated these events like a military range exercise. They planned, delegated responsibilities, and managed the schedule.

\section{Student-Veterans' Contributions to Success}

Veterans have unique qualities when compared to their non-veteran peers. These assets, according to Lord et al, are reflected by their "experience in planning, implementing, and leading teams" [4]. Additionally, these traits are bolstered by other attributes typically held by veterans such as problem-solving, organizational, and time management skills [2], [5]. This indicates a likelihood that student-veterans are better equipped to navigate difficult projects pressured by 
time and resource constraints. Student-veterans' experience and problem-solving abilities make them well-suited to technological projects and, more specifically, leadership roles within these program types [5], [6]. For this project, these traits combined to enable the student-veteran to adapt to the uncertainty caused by lack of familiarity with the design competition itself and university requirements for rocket launches, organize and influence others in spite of the lateness of the team's entry into the competition, and to enable the team to execute all required assignments given previously stated constraints and the large number of varied tasks which needed to be accomplished.

The technical, organizational, and logistical challenges were present throughout the entire design process. Both student-veterans and non-veteran students worked equally well in developing the technical solutions. This included analysis of various motors, structural design, and conception of the successful drag system. Within the operational and logistical categories, however, veteran attributes were directly responsible for mitigating unusual issues. Problem-solving, riskmanagement, and operational preparation begins at "boot camp" for all service members and continues to be embedded into the core of said personnel throughout their time spent in service. These skills were critical to the realization of all operational and logistical tasks as well as in managing a team of people with diverse skill sets and backgrounds.

For example, entering a highly technical design competition with no experience and two months behind other competitors may curtail the performance of many students. However, the three student-veterans in this group used the problem-solving, operational mindset learned from the military to communicate a clear vision to other team members with a focus on mission accomplishment; they did not allow themselves to be distracted by the calendar or overwhelmed by the number of tasks that needed to be addressed. Rather, the student-veterans worked to establish clear criteria and expectations for each member of the team to include requirements for students to make the competition's travel team and criteria for meeting and workgroup attendance. In this way, student-veterans provided a transparent and fair means of assessing each individual's contribution to the project which ultimately led to the team's success.

The competition also required each team to work with a mentor who was certified in high-power rocketry. The student-veterans worked very closely with the mentor to quickly familiarize the team with the fundamentals of model rocketry. Together, the project manager and mentor integrated the mentor's expertise into the rocket club in an accelerated manner. As a result, they were able to raise team expectations and enthusiasm for the design project. The team's mentor also mentored another team from another state university. The mentor worked with the Kent State team on a weekly basis; the team from the other university rarely contacted him. The mentor attributed his enthusiasm for our team's project to the maturity and poise and communication with the project manager.

Despite time constraints, the student-veterans also encouraged the team to maintain a "spirit of academia," beginning the design from first-principle fundamentals, rather than using the readily available rocket simulation software, RockSim ${ }^{\circledR}$. The design team used their own analyses to design the rocket and estimate performance, then used the RockSim® software to confirm and verify their own analytical results. This resulted in a deeper and "enduring understanding" [7] of the physics of rocket performance and design. 
Many non-veteran members of the team were initially resistant to this approach, but the studentveterans continued to influence and encourage the rest of the group. Their persistence paid off. The decision to begin with first-principles resonated well with the competition officials, since nearly every other team primarily used software as the basis of their performance predictions. In an interview with one non-veteran student team member, they said the following:

"Initially, given the time-constraints, I was concerned with the decision to use first-principles for the predictions, when RockSim ${ }^{\circledR}$ could have saved time. The leadership within the group though helped to subdue these concerns. Upon noticing that most of the competitors utilized the software programs to make their predictions, I felt a sense of accomplishment in our process and a boost of confidence. In the end, I think the judges were impressed with this decision, and I was able to be involved in applying academics I was about to undergo in my degree program" (A. Fertig, personal communication, January 22, 2018).

When inquiring about this decision to a student-veteran team member, they had this to say in comparison:

"I liked the idea of using academics over a computer simulation program to predict our rocket's performance and was not concerned given the timeconstraints. It provided us a foundational understanding of rockets and design. I believe it helped us to stand out in both our engineering solutions and standards in comparison to other competitors" (N. Figueroa, personal communication, January 22, 2018).

Team inexperience and safety concerns were also easily addressed by the student-veterans, specifically the safety officer, who is a veteran of the Ohio National Guard. As military members often deal with risk, mitigation tools are well-known and followed. The safety officer used his experience with this process to successfully integrate it into the club for each event involving some level of risk. The safety officer and project manager created a standard operating procedure (SOP) flight checklist and manual, a snapshot of which is presented in Figure 2. As a result, risk was controlled and mitigated throughout the design process and team activities, despite the use of hazardous solid propellants, black powder, and the hurried nature of the design process.

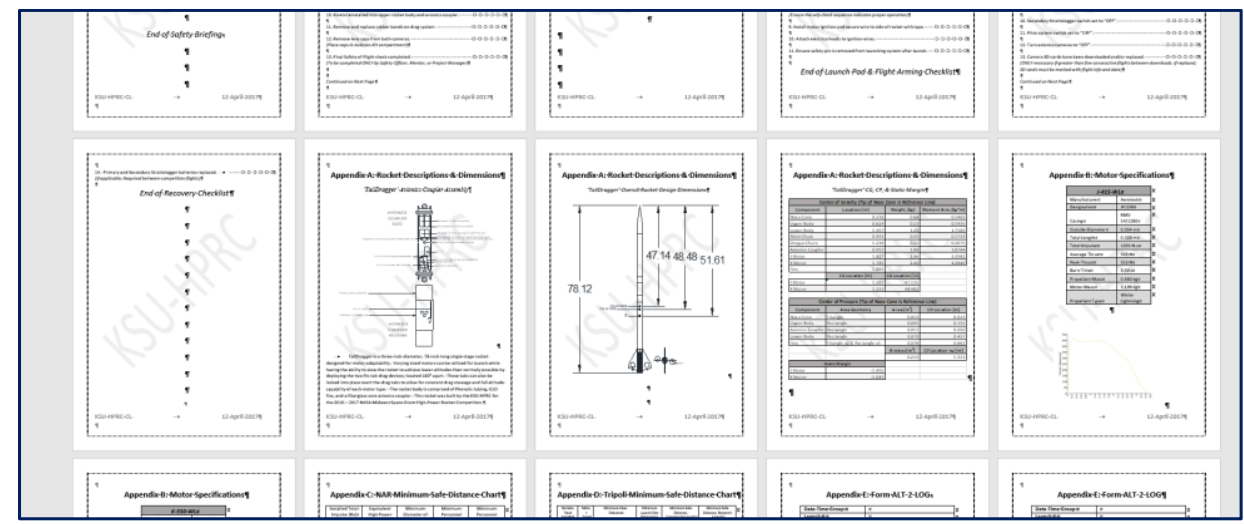


Figure 2: Extracts from student-veteran designed flight checklist and SOP

Logistical challenges primarily dealt with university and organizational issues. Developing university support was necessary to complete certain tasks. Two such tasks were community outreach and team familiarization. These meant the team needed to perform model rocket launches on university property and in the presence of campus infrastructure and young children. This further meant contacting departments at the university-level that dealt with infrastructure, legal, and public safety, many of which students have never interacted with during their time on campus. It may be intimidating for students who lack experience in communication within a hierarchical structure to contact a university department such as safety and risk compliance, with the intent of gaining permission to conduct these types of high-risk events. However, the project manager's military experience enabled him to effectively answer all questions and address the concerns of all these departments. The project manager was able to achieve university support for rocket club activities very easily, with little effort from the faculty advisor or other college employees.

Other logistical challenges included funding and managing deliverables. The project manager quickly worked with the faculty advisor to secure funding from the Ohio Space Grant Consortium. Additionally, the project manager had to manage the milestone and delivery schedule, which included the following:

- Preliminary technical report

- Flight readiness report

- Launch and recovery checklists

- Team familiarization and educational outreach activities

- Oral presentation

- Post-flight report

- A minimum of one test launch (the team conducted nine successful launches).

- A functional rocket capable of meeting the competition goals

Although much of the discussion has focused on how the student-veteran helped the Kent State University High-Power Rocket Club succeed in its competition, the influence of non-veterans on student-veteran learning should also be noted.

\section{Student-Veteran Learning Outcomes}

The literature documents difficulties that veterans have interacting with society at large, one of which is working with non-veterans, particularly students [8], [9]. This can affect student veterans who may perceive that they have little in common with their nonveteran peers on campus. Nevertheless. this interaction is important to achieve the fullness of an academic experience [1]. When the project was complete, the project manager and faculty advisor, also a veteran, discussed the interactions between student veterans and non-veterans on the team. They both noted some learning experiences on the part of the student-veterans. 
- The student-veterans learned the intricacies of dealing with a diverse population, not bound together by a military camaraderie or widespread like-minded thinking. Thus, the project manager needed to deal with disagreements in a non-authoritative, encouraging and influencing manner. This was especially critical during the "storming" phase of team formation [10].

- The student-veterans learned that ceding management or control of the design itself to the group as a whole resulted in a much better product with enthusiasm and buy-in from the whole team. The project manager managed the process: deadlines, milestones, resources and funding, etc. He influenced where he needed to, but otherwise let the group work.

- The project manager learned that saying "yes" to suggestions as often as possible yielded better results than saying "no."

- Reflection after execution is important, similar to the military after-action-review. The program manager discussed several lessons learned to include (1) allocating additional time for completing technical reports, and (2) mentoring/supervising the more inexperienced team members to ensure a task was completed correctly. The team correctly identified that addressing these two areas would have ensured a higher placement in the competition.

\section{Post-Competition Activities}

The KSU High-Power Rocket Club exists today as a structured organization that follows an integrated product team framework. The club's members are highly active in both competitive tasks and institutional outreach programs. They are continually requested to demonstrate model rocketry to middle-school and high-school students in support of institutional outreach activities. Having completed over 70 model rocket launches on university property to date without incident, the group has gained both the trust and support of the varying departments at the university. Student-veteran leadership in this inaugural team provided the framework for the organization, and benefited the team members, institution, and community. These can be summed up in three words: "professionalism, maturity, and poise" [3].

The team now focuses on aiding the institution and youth-community through the science of building rockets, as well as designing a new rocket for the 2018 competition. The club also presents learning opportunities through team membership for any college student interested, regardless of degree program. This may be a direct result of the student-veterans' contributions. According to one new member, who is majoring in public health, when asked about her experiences with this club, she said

"At first, I was a little nervous about becoming a member, but now I am comfortable. I feel like I am learning about physics and engineering concepts alongside my teammates. I can participate, and I can ask a question without feeling like it is stupid. I think the leadership helps to create this kind of atmosphere, that encourages the sharing of ideas and learning" (N. Patterson, personal communication, January 27, 2018).

The success of last year's team has spilled over to the current year. The success and professionalism of the team's efforts led to subsequent funding from the Ohio Space 
Grant Consortium and expansion to students from other colleges across campus. A student-veteran also volunteered to serve as project manager for the 2018 competition entry.

\section{Implications for the Engineering Community}

The implications for the greater engineering community are three-fold:

1. Student-veteran's participation in a club such as the Kent State University High-Power Rocket Club may help student retention and draw youth into STEM fields.

2. A student organization such as this can help student-veterans learn how to transition their skills into non-military engineering projects (Figure 3 ).

3. The student-veterans involved in the inaugural team can serve to demonstrate operational and logistical advantages over non-veteran students.

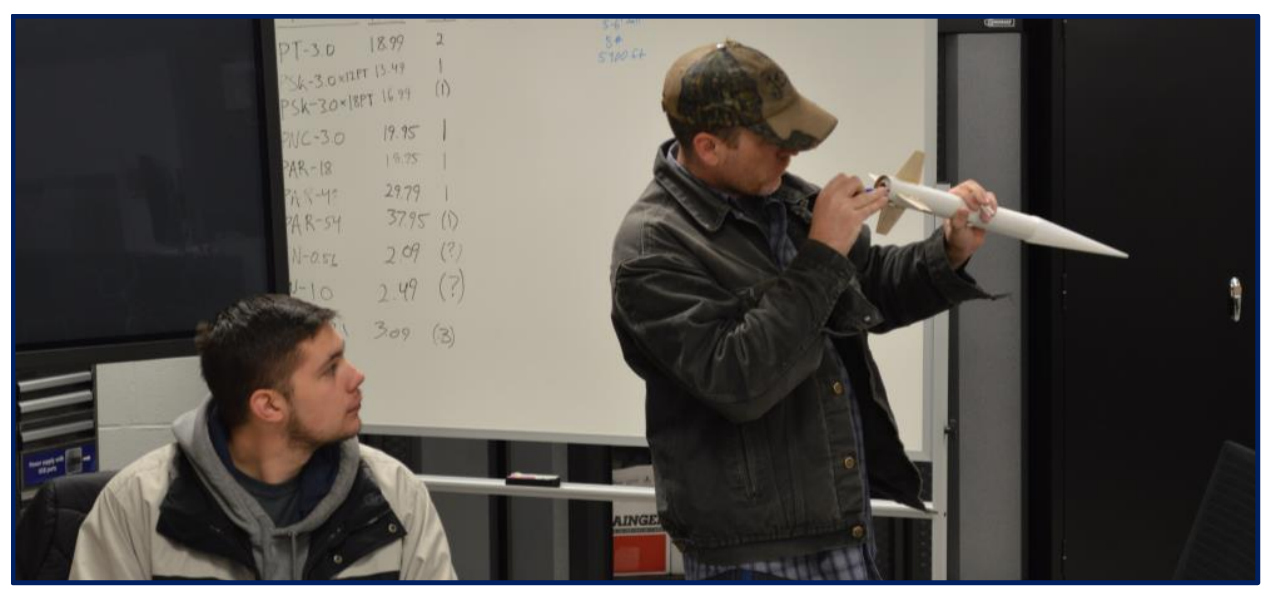

Figure 3: Student-veteran safety officer (left) and project manager/lead author (right) during rocket familiarization phase (with permission of the student-veterans)

According to Henderson, et. al., there are three practices that help administrations connect to student diversity. They are trust and relationship-building, respect and cultural sensitivity, and partnership [11]. Student-veterans can assist with this goal as the military instills a set of values into service-members, which is based around a code of ethics. For example, the Army values are leadership, duty, respect, selfless service, honor, integrity, and personal courage. These values build trust and partnerships. Student-veterans show somewhat greater cultural sensitivity," [1]. These values can also help to draw young and diverse students into STEM fields [12]. As a club such as the KSU High-Power Rocket Club actively participates in community outreach, studentveterans can play a major role in inspiration, motivation, and communication.

As student-veterans seek out activities upon transitioning into college life, a structured, hierarchical system as exits in student design projects may appeal greatly to them. As such, a student-organization such as this rocket club can help the student-veteran learn how to utilize their accumulated military skills and values in a civilian setting. This can be accomplished comfortably and over time as they are in an environment that may feel familiar as it contains aspects like military hierarchy, team building, and leadership. This can serve as a transitioning tool while teaching the student-veteran how to better serve in a civilian engineering community. 
The attributes added to the inaugural team by the student-veterans showed their ability to handle complex operational and logistical challenges. Whether environmental, institutional, time or resource-constrained, veterans can add advantages to a design team beyond that of typical nonveteran team members. This could translate into timely design completions, out-of-the-box design solutions, or simply team motivation for the greater engineering community.

\section{Future Research Opportunities}

The difficulty of military-to-university transition is well studied and documented and describe solutions often focused on service organizations. Although, these service organizations are typically devoted primarily to assisting the student-veteran in administrative tasks [13], [14]. What these programs do not seem to provide, is the type of environment veterans become suited to. Veterans grow comfortable with mission-centered, structured events during their military service, an environment not seemingly provided by service organizations [15]. These service organizations also seem to fall short of providing long-term, meaningful inclusiveness for student-veterans.

Longer-term studies focused on the effects of student-veteran involvement in STEM-based student-organizations may help to form a framework for long-term transitioning techniques. STEM-based student organizations, necessarily mission-oriented and structured, may serve to bridge the gap in transition follow-up by providing the type of atmosphere veterans are comfortable with. Furthermore, these organizations can remain available to student-veterans throughout their entire collegiate career, providing a lasting reintegration tool.

Another advantage that could be assessed with this research, is the ability of a studentorganization to reengage the student-veteran with the community. Non-veteran students currently interact with the community at a rate higher than that of student-veterans, $82 \%$, compared with $68 \%$ [1]. Technical-based clubs typically involve community outreach events and/or competitions, the Kent State University High-Power Rocket Club provides both, that give veterans greater opportunity and reward to this interaction.

Finally, the type of service should be addressed. The usefulness of long-term transitioning tools, such as a STEM-based student organization, may depend on whether the student-veteran was active-duty, national guard, or reserves. Other factors, such as length of service, length of break between service and academics, number and location of deployments, and injuries suffered, may all effect transitioning needs and level of willingness to become involved in student-life.

\section{Conclusion}

This paper presented the challenges encountered by an inaugural high-power rocket club in establishing itself as a design competition student organization, and how the attributes of studentveterans contributed to its great success. It then discussed the impact these student-veterans had on their peers and subsequent teams. A discussion followed asserting the potential impacts of student-based design teams on transitioning student-veterans, and the kind of impact this type of organization and student-veterans could have on the engineering community. Future research 
opportunities are then suggested that could help the academic, veteran, and engineering communities better understand the positive effects technical-based student organizations can have on these communities. Currently, another student-veteran is in the project manager position and this organization has a promising outlook.

\section{References}

[1] Y. M. Kim and J. S. Cole, "Student Veterans/Service Members' Engagement in College and University Life and Education," 2013.

[2] L. Gilles, "Bringing Stars \& Stripes into the MBA: Essential Lessons on Military Student Recruitment," Graduate Management News, 2017. [Online]. Available: https://www.gmac.com/why-gmac/gmac-news/gmnews/2017/august-2017/militarystudent-recruitment.aspx.

[3] R. J. Rabb, K. C. Bower, R. J. Barsanti, and Ronald W Welch, "Veteran Students in Engineering Leadership Roles," in Proceedings of the 124h ASEE Annual Conference \& Exposition, 2017.

[4] S. M. Lord, K. A. Kramer, R. T. Olson, M. Kasarda, D. Hayhurst, S. Rajala, R. Green, D. Soldan, R. Green, and D. Soldan, "Special Session - Attracting and Supporting Military Veterans in Engineering Programs," in 41st ASEE/IEEE Frontiers in Education Conference, 2011.

[5] D. B. Stringer and M. McFarland, "Veterans' Contributions to Enhancing the Capstone Learning Experience of Engineering Cohorts," in Proceedings of the 123rd ASEE's Annual Conference \& Exposition, 2016.

[6] M. D. Mumford, S. J. Zaccaro, F. D. Harding, T. O. Jacobs, and E. A. Fleishman, "Leadership Skills for a Changing World: Solving Complex Social Problems," Leadersh. $Q$. , vol. 11, no. 1, pp. 11-35, 2000.

[7] A. Cummings and W. Oakes, "Helicopter Aerodynamics and Design Course Developed from a Research-Informed Framework," in Proceedings of the 122nd ASEE Annual Conference \& Exposition, 2015.

[8] V. Schiavone and D. Gentry, "Veteran-Students in Transition at a Midwestern University," J. Contin. High. Educ., vol. 62, no. 1, pp. 29-38, 2014.

[9] M. Thompson, "The Other 1\{\%\}," Time, p. 34, 2011.

[10] Dieter and Schmidt, Engineering Design, 5th ed. McGraw-Hill, 2013.

[11] A. T. Henderson and K. L. Mapp, "A New Wave of Evidence: The Impact of School, Family, and Community Connections on Student Achievement," SEDL, 2002.

[12] S. Laursen, C. Liston, H. Thiry, and J. Graf, "What Good Is a Scientist in the Classroom ? Participant Outcomes and Program Design Features for a Short- Duration Science Outreach Intervention in K - 12 Classrooms," Life Sci. Educ., vol. 6, no. 1, pp. 49-64, 2007.

[13] M. Elliott, C. Gonzalez, and B. Larsen, "U.S. Military Veterans Transition to College : Combat, PTSD , and Alienation on Campus," J. Stud. Aff. Res. Pract., vol. 48, no. 3, pp. 279-296, 2011.

[14] D. Diramio, R. Ackerman, and R. L. Mitchell, "From Combat to Campus : Voices of Student-Veterans," NASPA J., vol. 45, no. 1, pp. 73-102, 2008.

[15] D. T. Vacchi, "Considering Student Veterans on the Twenty-First-Century College Campus," About Campus, no. May-June, pp. 15-22, 2012. 